\title{
The Fall and Rise of State Aid in Brexit Britain: The Chequers Plan
}

'A rigorous State aid system (..) is good for taxpayers and consumers, and ensures an efficient allocation of resources'. The source of such a glowing assessment of the virtues of a system of State aid control may come as a surprise to many. It is actually contained in the so-called Chequers Plan ('The Future Relationship between the United Kingdom and the European Union', of July 2018), the UK proposal for a comprehensive trade association agreement with the EU. A surprise, as State aid was rapidly identified in the aftermath of the Brexit referendum as one of the areas of EU law that had to be more urgently abandoned. A cross party consensus emerged in identifying State aid rules as a bureaucratic nuisance to pursuing more pro-business deregulatory policies or, depending on your political preferences, as an obstacle to more socially responsible policies. As the reality of negotiations quickly kicked in, it became apparent that the EU was in no mood to conclude an agreement that did not contain rules that prevent the UK from granting anti-competitive aid. As stated in the EU Council Guidelines of 23 March 2018:

Given the UK's geographic proximity and economic interdependence with the EU27, the future relationship will only deliver in a mutually satisfactory way if it includes robust guarantees which ensure a level playing field. The aim should be to prevent unfair competitive advantage that the UK could enjoy through undercutting of levels of protection with respect to, inter alia, competition and state aid, tax, social, environment and regulatory measures and practices. This will require a combination of substantive rules aligned with EU and international standards, adequate mechanisms to ensure effective implementation domestically, enforcement and dispute settlement mechanisms in the agreement as well as Union autonomous remedies, that are all commensurate with the depth and breadth of the EU-UK economic connectedness.

The UK replied with its 'Chequers Plan' that commits the UK to maintaining 'robust' State aid control. This robustness should be guaranteed in three ways: a) the adoption of a common rulebook; b) a continuous process of harmonization with EU rules; and c) a further duty imposed on national courts to ensure consistency with EU law. Consequently, first of all, there will be a 'book containing the official rules for an organization or activity' (that's the Cambridge dictionary definition of a rulebook) that will be common to both the UK and the EU. However, the 'commonality' is in reality a mere adoption by the UK of the existing EU rules on State aid. Therefore, some slides (slides are fast becoming a sort of new source of law in these Brexit days...) prepared last July by Her Majesty's Government specify that the new UK legislative framework will have the same content as the EU regime and will mirror all relevant EU rules. This would mean replicating Articles 107, 108 and 109 of the Treaty, and arguably the case law of the Court of Justice interpreting these provisions as well. Actually, the State aid Treaty articles have already received some kind of 'protection'. As is well known, on 29 March 2019, the European Union (Withdrawal) Act 2018 will repeal the European Communities Act 1972, the UK act of accession to the then EEC. The European Union (Withdrawal) Act provides 
that the EU acquis will remain relevant within the UK unless and until the Government decides otherwise. As far as State aid is concerned, Article 108(3) TFEU is listed in the European Union (Withdrawal) Act as one of the rights and obligations recognised in domestic law. Article 108 (3) contains the so-called stand still clause, which prevents Member States from granting any aid which has not been approved by the Commission, and it is the only provision within the State aid framework which is capable of producing direct effect, with all its well-known ramifications. The Government's slides also inform us that 'all regulations underpinning the Treaty articles' will be preserved. It would be interesting to know what kind of status Commission decisions and the deluge of soft law instruments - communications, notices, non-papers, etc - will be given under the new domestic UK law system. Who knows, maybe, and paradoxically, the UK's detachment might provide some kind of indirect clarification on the nature of these instruments, a vexata questio in EU law. A notable exception to the 'domestication' of State aid law is actually taxation. Thoughts are naturally drawn immediately to the pending Commission investigations into the Gibraltar Tax Corporation and the UK's CFC rules...

A further intriguing question is about the precise scope of the common rulebook. As is well known, the commitment to the common rulebook is limited by the Chequers Plan to the free movement of goods, whilst in other areas, such as services, the UK reserves its right to diverge. In State aid related areas, such as transport and energy, the Chequers Plan speaks of 'co-operation' with the EU. The same UK Government slides clarify that the State aid provisions will apply across the whole economy, thereby creating a curious mismatch, because whilst the UK is reserving its right to go separate ways in many sectors, it will remain bound by State aid rules.

In order to keep the common rulebook 'common', the Chequers Plan also commits the UK to a continuous process of 'ongoing harmonization' which is a peculiar choice of words in the context of the withdrawal negotiations with the EU. 'Harmonization' has very precise legal meaning in the EU legal system and it refers to the removal of national obstacles to trade and the replacement of those divergent standards with a supranational common standard - a process involving a policy making decision about the most appropriate level of regulation. One can only wonder if such EU-strong terminology would really work in a bilateral relationship such as that which will be between the EU and the UK. Still, the burden of making such a process work will fall on the shoulders of a future Joint-Committee, or in actual fact Committees with different portfolios. These bodies will have the task of providing a process of updating, adapting, problem solving, dispute pre-settlement, etc, but as State aid is actually an area which is in constant evolution, despite being there since the very beginning of the process of European integration, one can only wish the members of those Committees well. A further guarantee for the integrity of the common rulebook should be provided by national courts, which 'will ensure that there is consistent interpretation of State aid rules. In particular UK courts would pay due regard to the CJEU's case law, where relevant to the matter before the court'. Again, the terminology is a bit disconcerting from the perspective of EU law, because 'consistent interpretation' is a general principle of EU law that requires national courts to interpret national law according to the scope and purpose of EU law. This surely cannot have been the intention, because the only duty imposed on national courts is to have 'due regard' to EU law. Interestingly, the European Union (Withdrawal) Act 2018 requires national courts to consider post-exit CJEU case law if they consider it appropriate to do so. We shall see how common law courts, in their independence, will feel inclined to interpret the expression 'due regard' and 'appropriate to do so'. Finally, the Chequers Plan goes as far as to suggest a possi- 
ble dispute settlement if the Joint Committee fails to find an agreement on possible divergences, or in cases of violations of the future Treaty by one party: an independent arbitration panel with a possible reference to the CJEU if the question concerns EU law (and what else would the question be about?). This is an issue which should be the object of another editorial, but with the current stand-off between arbitration and EU law as exemplified by the Achmea litigation, the UK proposal does not bode too well.

Perhaps the least challenging question will be how to set up a domestic system of State aid control. The Competition Market Authority (CMA) is the authority identified by the Government to perform an equivalent role to that of the European Commission. The CMA has an international reputation for independence and expertise, but as the current flurry of job opportunities there shows, it still requires some more personnel with experience in dealing with State aid matters. Still, the task might be less daunting than it looks. First, it will probably be able to rely on the wide experience of BIS, the government Department 'specialized' in State aid matters. Second, notifications might not be so frequent due to the horizontal economic structure of the UK and the GBER can easily be taken as a model for the CMA. Yet, in its new role, the CMA will have to challenge the behaviour of State measures, including governmental decisions and possibly even primary legislation, with all the possible 'constitutional' implications that this invokes, a role that it has never previously performed. It will also be incumbent on the CMA to gradually develop, in applying the grounds of compatibility, a new concept of a UK-wide 'common good', which would promote territorial cohesion and solidarity between the several regions of the UK, as well as innovative investments, protection of our air, and efficient transport. On second thought, this might be the greatest challenge, not just for the CMA, but also for a post-Brexit United Kingdom.

Andrea Biondi 